\title{
Non-invasive haemodynamic assessments among hypertensive patients in a routine family doctor's office
}

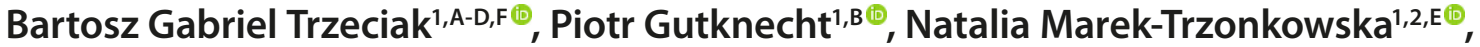 \\ Andrzej Molisz ${ }^{3, C \oplus}$, Rafał Czaja ${ }^{4, B \oplus}$, Janusz Siebert ${ }^{1, A, C, E-F \oplus}$ \\ ${ }^{1}$ Department of Family Medicine, University Centre for Cardiology, Medical University, Gdansk, Poland \\ ${ }^{2}$ Laboratory of Immunoregulation and Cellular Therapies, International Centre for Cancer Vaccine Science, Medical \\ University, Gdańsk, Poland \\ ${ }^{3}$ Medical University, Gdansk, Poland \\ ${ }^{4}$ Non-public Healthcare Institution 'Clinic Nova Banino", Banino, Poland \\ A - Research concept and design, B - Collection and/or assembly of data, C - Data analysis and interpretation, \\ $D$ - Writing the article, E-Critical revision of the article, F-Final approval of the article
}

Trzeciak BG, Gutknecht P, Marek-Trzonkowska N, Molisz A, Czaja R, Siebert J. Non-invasive haemodynamic assessments among hypertensive patients in a routine family doctor's office. Ann Agric Environ Med. 2022; 29(2): 264-268. doi: 10.26444/aaem/143163

\begin{abstract}
Introduction and objective. Difficult-to-control blood pressure can be attributed to a mismatch between the haemodynamic type of hypertension and the drug class used in treatment. Impedance cardiography may be a useful tool for enabling the individualization of antihypertensive therapy. The aim was to investigate the distribution of haemodynamic types of HT among hypertensive patients in an outpatient clinic.

Materials and method. This was a prospective, observational study of patients with primary hypertension at an outpatient clinic. A 10-minute ICG examination was performed in 189 consecutive, patients (118 men and 71 women). Patients were divided into groups based on whether their hypertension was well-controlled $(140 / 90 \mathrm{mmHg}, \mathrm{n}=95)$. They were also stratified according to haemodynamic states.

Results. Patients with poorly controlled blood pressure compared to patients with well controlled blood pressure had a high haemodynamic output in $6.3 \%$ vs. $2.1 \%(p=0.153)$, and high vascular resistance in $41.1 \%$ vs. $27.7 \%(p=0.037)$, and balanced haemodynamic states in $52.6 \%$ vs. $70.2 \%$ ( 080 beats $/ \mathrm{min}$ ) and fluid retention $(p<0.01)$.

Conclusions. Half of the examined patients did not achieve the therapeutic goals for hypertension treatment. Differences in haemodynamic state of well and poor controlled hypertension groups suggests the usefulness of impedance cardiographytargeted hypertension treatment.
\end{abstract}

\section{Key words}

cardiovascular diseases, blood pressure, arterial hypertension, impedance cardiography, hemodynamic indices, hemodynamic state

\section{INTRODUCTION}

Hypertension (HT) is one of the most common cardiovascular disease worldwide. It is estimated to affect over $30 \%$ of the world's population, with rates rising significantly in the elderly population $[1,2,3]$. Currently, HT is the most frequent reason for patient visits to family care physicians in the USA [4]. Despite national health promotion programs and progress in anti-hypertensive drug development, HT remains a major risk factor for morbidity and mortality worldwide $[5,6]$ and most patients treated for HT do not achieve appropriate blood pressure control [1]. The main causes of poor control of HT are poor adherence to prescribed medicines, white-coat phenomenon, clinician inertia, insufficient use of combination treatment, lifestyle factors (excessive alcohol consumption, and high sodium intake), as well as the intake of substances that increase blood pressure or act antagonistically to antihypertensive drugs, and the complexity of current treatment strategies [7]. Efforts have

Address for correspondence: Bartosz Gabriel Trzeciak, Medical University of Gdansk Department of Family Medicine, University Centre for Cardiology, Gdańsk, Poland E-mail: bartolomi@gumed.edu.pl

Received: 12.08.2021; accepted: 18.10.2021; first published: 06.12.2021 been made to improve the treatment of resistant hypertension [8] and to improve arterial blood pressure control by the use of modern technologies [9]. In a meta-analysis from 2021, professionally-led interventions have been effective and led to an almost $5 \mathrm{mmHg}$ decrease of SBP [10], which inspires optimism for the future actions. Additionally, the choice of fourth-line antihypertensive pharmacotherapy is usually based on physician preference and experience, while the necessary treatment may be related to the haemodynamic type of hypertension [11, 12]. A profile with high vascular resistance and hyperkinetic/hyperdynamic circulation are the basic hypertensive states. A balanced state is recognized in the case of combination of the haemodynamic parameters, even though all of them might fit within the normal values. Fluid retention might also influence blood pressure levels. Difficulty with controlling a patient's blood pressure can often be attributed to a mismatch between drug class and the hypertensive state present in a patient [13].

The current European Society of Cardiology (ESC) guidelines recommend an individualization of the therapy based on evaluation of a patient's risk factors [7, 14]. Inoffice manual blood pressure measurements do not show the underlying circulatory system pathology or haemodynamic 
aberrations, such as increased systemic vascular resistance, fluid retention or cardiac output. According to the guidelines, there are five basic antihypertensive drug classes: angiotensinconverting-enzyme inhibitors (ACEI), angiotensin receptor blockers (ARB) and calcium channel blockers (CCB), which are classified as vasodilators (therefore should be prescribed in high vascular resistance type of $\mathrm{HT}$ ), and beta-blockers (BB) reduce contractility of the heart muscle (recommended in high output type of HT). Furthermore, diuretics should be admitted in the case of fluid retention. Impedance cardiography (ICG) examination learning curve is short and can be performed by a nurse or technician (the procedure is similar to ECG test). ICG is a non-invasive, reliable, operator-independent and reproducible technique for the measurement of haemodynamic states in patients with $\mathrm{HT}$ and cardiac failure [15]. It is an easy to use method which allows for the evaluation of haemodynamic parameters, and has been validated with invasive monitoring methods $[16,17]$. Previously published studies have shown that ICG allows for more targeted choice, titration and monitoring of antihypertensive medication, but were not conducted in primary care outpatient clinic $[18,19]$.

The current study shows the distribution of haemodynamic profiles between the patients with well controlled and poorly controlled hypertension as the basis for introducing ICGguided hypertension treatment.

\section{OBJECTIVE}

The aim of the study was to investigate the distribution of haemodynamic types of HT among hypertensive patients in an outpatient clinic.

\section{MATERIALS AND METHOD}

A total of 189 consecutive patients who had been previously diagnosed and treated for primary hypertension visiting family doctor's office were included in the study. The study group consisted of 118 men and 71 women. All patients underwent a 10 -minute ICG examination in a sitting position in standard blood pressure measurement conditions according to ESC guidelines. The blood pressure was taken in two-minute intervals. Values achieved in the last two intervals were analyzed. The exclusion criteria were as follows: an acute coronary syndrome within two previous months, an exacerbation of heart failure, diagnosed secondary hypertension, need for haemodialysis, severe aortic stenosis, and pregnancy. For non-invasive haemodynamic measurements the Niccomo (Non-Invasive Continuous Cardiac Output Monitor by Medis) device was used. The following parameters were measured or calculated: Body Mass Index [BMI], Blood Pressure [BP], Heart Rate [HR], Cardiac Index [CI], Systemic Vascular Resistance Index [SVRI], Thoracic Fluid Content [TFC], Heather Index [HI], Stroke Volume [SV], Stroke Index [SI], Left Cardiac Work [LCW], Left Cardiac Work Index [LCWI]. The echocardiography findings and laboratory tests were also collected.

For further analysis patients were divided into two groups according to effectiveness of blood pressure control: the well-controlled HT (wcHT) $(\mathrm{BP}<140 / 90 \mathrm{mmHg}, \mathrm{n}=94)$ and the poorly-controlled HT (pcHT) $(\mathrm{BP} \geq 140 / 90 \mathrm{mmHg}, \mathrm{n}=95)$.
The data were analyzed according to the haemodynamic states seen in hypertensive patients, as published by Krzesiński [20]. To make it clear, three main HD states are presented: High Output $\left(\mathrm{CI} \geq 4.2 \mathrm{~L} / \mathrm{min} / \mathrm{m}^{2}\right.$ and SVRI $<2580$ dyn $\mathrm{x} \mathrm{s}$ $\mathrm{x} \mathrm{cm}-5 \mathrm{x} \mathrm{m}^{2}$ ), High Vascular Resistance (SVRI $\geq 2580$ dyn $\mathrm{x}$ $\mathrm{s} \times \mathrm{cm}-5 \times \mathrm{m}^{2}$ and $\mathrm{CI}<4.2 \mathrm{~L} / \mathrm{min} / \mathrm{m}^{2}$ ), Balanced $(\mathrm{CI}<4.2 \mathrm{~L} /$ $\mathrm{min} / \mathrm{m}^{2}$ and $\mathrm{SVRI}<2580$ dyn $\mathrm{x} \mathrm{s} \times \mathrm{cm}-5 \times \mathrm{m}^{2}$ ). Additionally, subjects with (TFC women $>24$, men $>341 / \mathrm{kOhm}$ ) or without (TFC women $\geq 24$, men $\geq 341 / \mathrm{kOhm}$ ) fluid retention and high HR ( $\geq 80 / \mathrm{min})$ were also defined within these three subpopulations.

This was a retrospective and single-center study conducted according to the Declaration of Helsinki, and the protocol was reviewed and approved by the local Ethics Committee. All patients gave written informed consent for participation.

Statistical analysis. Student t-test and Mann-Whitney U test were used for quantitative variables. The normality of distribution was assessed by Shapiro-Wilk W test. The qualitative variables were compared by the means of Pearson's $\chi 2$ test. The statistical significance of $\alpha=0.05$ was set. The STATISTICA 12 by StatSoft and Microsoft Excel were used to perform statistical analysis.

\section{RESULTS}

The characteristics of the 189 hypertensive patients is presented in Table 1 .

The wcHT patients presented with significantly lower BP, HDL concentration, SVRI and LCWI, compared to pcHT subjects. Both groups were similar in terms of age, gender and BMI. The incidence of DM, CAD, measured ejection fraction and retinopathy showed no statistically significant difference between groups.

The difference in hemodynamic state between the groups is clearly visible. In the pcHT group there is higher HR, CI (no statistical significance, a small number of patients), TFC and SVRI observed more often compared to wcHT group (Tab.2).

A high resistance profile was found more often in the pcHT group, which suggests that low doses of vasodilators were used.

Within the pcHT group, six patients had high output, four of whom had high TFC values (66.6\%). At the same time, in the wcHT group, a high output and high TFC values were observed in two individuals. Within patients with a high resistance profile, there was a significant difference in the rates of fluid retention - high TFC value was found in $48.7 \%(n=19)$ of patients with pcHT and $42.3 \%(n=11)$ of patients with wcHT. When data of patients with a balanced haemodynamic profile were analyzed, high TFC values were found more often in the pcHT than in wcHT group $(56 \%-28$ patients vs. $48.4 \%$ - 32 patients), suggesting that low doses of diuretics were used (Tab. 3).

Analyzing particularly the groups of drugs used, a significant difference in effectiveness was found only for CCB. Most patients (59.8\%) received two or three drugs (Tab. 4). 
Table 1. Characteristics of 189 hypertensive patients in two groups according to hypertension (HT) control

\begin{tabular}{|c|c|c|c|c|}
\hline & Overall & $\begin{array}{c}\mathrm{BP} \geq 140 / 90 \mathrm{mmHg} \\
(\mathrm{pcHT})\end{array}$ & $\begin{array}{c}\mathrm{BP}<140 / 90 \mathrm{mmHg} \\
(\mathrm{wcHT})\end{array}$ & $P$ \\
\hline$n$ & 189 & 95 & 94 & \\
\hline $\mathrm{Ag}$ [years] & $59.9 \pm 13.3$ & $60.9 \pm 13.4$ & $58.9 \pm 13.2$ & 0.338 \\
\hline Male [\%] & 62.4 & 62.1 & 62.8 & 0.925 \\
\hline BMI $\left[\mathrm{kg} / \mathrm{m}^{2}\right]$ & $29.7 \pm 5,0$ & $29.8 \pm 5.4$ & $29.6 \pm 4,6$ & 0.595 \\
\hline HR [beats/min] & $68.6 \pm 11,0$ & $69.4 \pm 11.4$ & $67.9 \pm 10,6$ & 0.468 \\
\hline $\mathrm{SBP}[\mathrm{mmHg}]$ & $138.8 \pm 20,3$ & $152.7 \pm 18.2$ & $124.9 \pm 10,2$ & $<0.001^{*}$ \\
\hline $\mathrm{DBP}[\mathrm{mmHg}]$ & $83.3 \pm 11.9$ & $89.2 \pm 12.2$ & $77.3 \pm 8.1$ & $<0.001^{*}$ \\
\hline $\mathrm{Cl}\left[\mathrm{L} / \mathrm{min} / \mathrm{m}^{2}\right]$ & $3.09 \pm 0.64$ & $3.2 \pm 0.63$ & $3.0 \pm 0.6$ & $0.032^{*}$ \\
\hline $\mathrm{SI}\left[\mathrm{ml} / \mathrm{m}^{2}\right]$ & $47.0 \pm 15.5$ & $48.0 \pm 15.2$ & $46.0 \pm 15.7$ & 0.244 \\
\hline TFC [1/kOhm] & $30.4 \pm 5.9$ & $30.9 \pm 6.1$ & $29.9 \pm 5.6$ & 0.341 \\
\hline $\begin{array}{l}\text { SVRI } \\
{\left[\text { dyn } \times \mathrm{s} \times \mathrm{cm}^{-5} \times \mathrm{m}^{2}\right]}\end{array}$ & $2446 \pm 587$ & $2549 \pm 579.5$ & $2343 \pm 579$ & $0.005^{*}$ \\
\hline LCWI $\left[\mathrm{kg} \times \mathrm{m} / \mathrm{m}^{2}\right]$ & $3.9 \pm 1.1$ & $4.4 \pm 1.1$ & $3.4 \pm 0.8$ & $<0.001 *$ \\
\hline $\begin{array}{l}\text { Glucose } \\
\text { concentration } \\
{[\mathrm{mg} / \mathrm{dl}]}\end{array}$ & $\begin{array}{c}110.0 \pm 32.2 \\
(n=121)\end{array}$ & $\begin{array}{c}106.8 \pm 28.8 \\
(n=57)\end{array}$ & $\begin{array}{c}112.8 \pm 35.0 \\
(n=64)\end{array}$ & 0.307 \\
\hline $\begin{array}{l}\text { Total cholesterol } \\
\text { level }[\mathrm{mg} / \mathrm{dl}]\end{array}$ & $\begin{array}{c}206.5 \pm 48.0 \\
(n=129)\end{array}$ & $\begin{array}{c}214.5 \pm 44.7 \\
\quad(n=63)\end{array}$ & $\begin{array}{c}198.8 \pm 50.1 \\
(n=66)\end{array}$ & $0.063^{*}$ \\
\hline $\begin{array}{l}\text { Triglycerides } \\
{[\mathrm{mg} / \mathrm{dl}]}\end{array}$ & $\begin{array}{c}140.1 \pm 74.0 \\
(n=127)\end{array}$ & $\begin{array}{c}132.7 \pm 64.5 \\
(n=62)\end{array}$ & $\begin{array}{c}147.1 \pm 81.9 \\
(n=65)\end{array}$ & 0.405 \\
\hline LDL [mg/dl] & $\begin{array}{c}128.6 \pm 45.5 \\
(n=126)\end{array}$ & $\begin{array}{c}132.7 \pm 38.0 \\
(n=61)\end{array}$ & $\begin{array}{c}124.8 \pm 51.6 \\
(n=65)\end{array}$ & 0.115 \\
\hline $\mathrm{HDL}[\mathrm{mg} / \mathrm{dl}]$ & $\begin{array}{c}52.4 \pm 14.1 \\
(n=127)\end{array}$ & $\begin{array}{c}55.7 \pm 15.7 \\
(n=61)\end{array}$ & $\begin{array}{c}49.5 \pm 11.7 \\
(n=66)\end{array}$ & $0.036^{*}$ \\
\hline $\begin{array}{l}\text { eGFR } \\
{\left[\mathrm{ml} /\left(\min \times 1,72 \mathrm{~m}^{2}\right]\right.}\end{array}$ & $\begin{array}{c}79.5 \pm 20.8 \\
(n=129)\end{array}$ & $\begin{array}{c}79.5 \pm 19.2 \\
(n=61)\end{array}$ & $\begin{array}{c}79.5 \pm 22.2 \\
(n=68)\end{array}$ & 0.996 \\
\hline $\begin{array}{l}\text { Duration of HT } \\
\text { [years] }\end{array}$ & $10.2 \pm 8.9$ & $10.7 \pm 9.5$ & $9.7 \pm 8.3$ & 0.682 \\
\hline DM [\%] & 23.5 & 20.9 & 26.1 & 0.407 \\
\hline CAD [\%] & 25.0 & 23.7 & 26.5 & 0.570 \\
\hline Mean EF [\%] & $\begin{array}{l}62.6 \pm 8.1 \\
(n=116)\end{array}$ & $\begin{array}{c}62.7 \pm 5.4 \\
(n=57)\end{array}$ & $\begin{array}{c}62.6 \pm 10 \\
(n=59)\end{array}$ & 0.209 \\
\hline $\begin{array}{l}\text { Hypertensive } \\
\text { retinopathy }\end{array}$ & $\begin{array}{c}52(80 \%) \\
(n=65)\end{array}$ & $\begin{array}{c}24(75 \%) \\
(n=32)\end{array}$ & $\begin{array}{c}28(84.8 \%) \\
(n=33)\end{array}$ & 0.321 \\
\hline \multicolumn{5}{|c|}{$\begin{array}{l}\text { wCHT - well-controlled hypertension group; pcHT - poorly controlled hypertension group; } \\
\text { BMI - Body Mass Index; SBP - Systolic Blood Pressure; DBP - Diastolic Blood Pressure; HR - } \\
\text { Heart Rate; } \mathrm{Cl} \text { - Cardiac Index; SVRI - Systemic Vascular Resistance Index; TFC Thoracic Fluid } \\
\text { Content; } \mathrm{HI} \text { - Heather Index; ACI-Acceleration Index; SI - Stroke Index; DM - Diabetes Mellitus; } \\
\text { HT - Hypertension; CAD - Coronary Artery Disease; EF - Ejection Fraction; } n \text { - number of } \\
\text { examined patients; }{ }^{*} p<0.05 \text {. }\end{array}$} \\
\hline
\end{tabular}

Table 2. Basic elevated hemodynamic parameters in the group of well and poorly controlled hypertension (HT)

\begin{tabular}{|c|c|c|c|}
\hline & $\begin{array}{c}\mathrm{BP} \geq 140 / 90 \mathrm{mmHg} \\
(\mathrm{pcHT})\end{array}$ & $\begin{array}{c}\mathrm{BP}<140 / 90 \mathrm{mmHg} \\
\quad(\mathrm{wcHT})\end{array}$ & $\mathrm{p}$ \\
\hline & $\mathrm{n}=95$ & $n=94$ & \\
\hline $\begin{array}{l}H R \geq 80 \\
{[1 / \mathrm{min}]}\end{array}$ & $16(16.8 \%)$ & 10 (10.6\%) & $<0.01^{*}$ \\
\hline $\begin{array}{l}\mathrm{Cl} \geq 4,2 \\
{\left[\mathrm{~L} / \mathrm{min} / \mathrm{m}^{2}\right]}\end{array}$ & $6(6.3 \%)$ & $2(2.1 \%)$ & 0.56 \\
\hline $\begin{array}{l}\text { TFC } \\
M \geq 34, K \geq 24 \\
{[1 / k O h m]}\end{array}$ & 51 (53.7\%) & 45 (47.9\%) & $<0.01^{*}$ \\
\hline $\begin{array}{l}\text { SVRI } \geq 2580 \\
{\left[\text { dyn } \times \text { s } \times \mathrm{cm}^{-5} \mathrm{x} \mathrm{m}^{2}\right]}\end{array}$ & 39 (41.1\%) & 30 (31.9\%) & $<0.01 *$ \\
\hline
\end{tabular}

Table 3. Haemodynamic profiles in the group of well and poorly controlled hypertension

\begin{tabular}{|c|c|c|c|}
\hline & $\begin{array}{c}B P \geq 140 / 90 m m H g \\
(p c H T)[\%]\end{array}$ & $\begin{array}{c}\mathrm{BP}<140 / 90 \mathrm{mmHg} \\
(\mathrm{wcHT})[\%]\end{array}$ & $\mathrm{p}$ \\
\hline$n$ & 95 & 94 & \\
\hline $\begin{array}{l}\mathrm{Cl}<4,2\left[\mathrm{~L} / \mathrm{min} / \mathrm{m}^{2}\right] \\
\mathrm{SVRl} \geq 2580\left[\text { dyn } \times \mathrm{s} \times \mathrm{cm}^{-5} \times \mathrm{m}^{2}\right] \\
\text { High Resistance }\end{array}$ & $40(42.1 \%)$ & $26(27.7 \%)$ & $0.037^{*}$ \\
\hline $\begin{array}{l}\mathrm{Cl}<4,2\left[\mathrm{~L} / \mathrm{min} / \mathrm{m}^{2}\right] \\
\mathrm{SVRl}<2580\left[\mathrm{dyn} \times \mathrm{s} \times \mathrm{cm}^{-5} \times \mathrm{m}^{2}\right] \\
\text { Balanced }\end{array}$ & 49 (51.6\%) & $66(70.2 \%)$ & $0.009^{*}$ \\
\hline $\begin{array}{l}\mathrm{Cl} \geq 4,2\left[\mathrm{~L} / \mathrm{min} / \mathrm{m}^{2}\right] \\
\mathrm{SVRl}<2580\left[\text { dyn } \times \mathrm{s} \times \mathrm{cm}^{-5} \times \mathrm{m}^{2}\right] \\
\text { High Output }\end{array}$ & $6(6.3 \%)$ & $2(2.1 \%)$ & 0.153 \\
\hline
\end{tabular}

wcHT - well controlled hypertension group; $\mathrm{pcHT}$ - poorly controlled hypertension group; $\mathrm{Cl}$ - Cardiac Index; SVRI - Systemic Vascular Resistance Index; ${ }^{*} \mathrm{p}<0.05$.

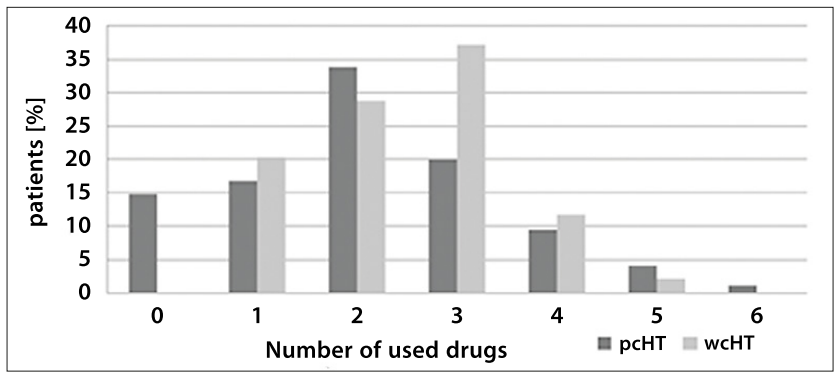

Figure 1. Antihypertensive drugs used in two groups $(n=189)$ : poorly vs. well controlled hypertension

Table 4. Pharmacotherapy in the group of 189 hypertensive patients

\begin{tabular}{|c|c|c|c|c|c|c|c|}
\hline & ACE-I & ARB & $\mathrm{CCB}$ & Any vasodilator & BB & Diuretics & Alpha-blockers (doxazosin) \\
\hline $\begin{array}{l}\mathrm{BP}<140 / 90 \mathrm{mmHg} \\
(\mathrm{wcHT}) \mathrm{n}=94\end{array}$ & $52(55.3 \%)$ & $25(26.6 \%)$ & $46(48.9 \%)$ & $83(88.3 \%)$ & $58(61.7 \%)$ & $44(46.8 \%)$ & $7(7 \%)$ \\
\hline$p$ & 0.421 & 0.965 & $0.015^{*}$ & 0.082 & 0.160 & 0.345 & 0.459 \\
\hline
\end{tabular}

wcHT - well controlled hypertension group; pcHT - poorly controlled hypertension group; ACE-I - ACE-inhibitors; ARB - angiotensin receptor blocker; CCB - calcium channel blockers; BB - betablockers; ACE-I - any vasodilator and/or ARB and/or CCB and/or doxazosin]; * $p<0.05$ 


\section{DISCUSSION}

Although hypertension is treated mainly by family physicians, despite the large number of different antihypertensive medications and the relative ease of monitoring the disease, many patients continue to have poor control of their blood pressure [21]. In the current study, almost 50\% of patients were in the poor HT control group. However, ICG has not yet been approved as a first-line tool for the identification and stratification of hypertension. This study analyzes the haemodynamic parameters in hypertensive patients using ICG during routine visits to a family doctor with the aim of determining the haemodynamic states in hypertensive patients in a primary care setting. There is no easy way to discern between the possible hypertensive state of a patient performing standard physical examination without using ICG. The use of ICG-guided treatment is easy to evaluate and enables tailored antihypertensive therapy to a specific haemodynamic type of HT, such as high vascular resistance, high output (another term used in the literature is hyperkinetic/hyperdynamic), fluid retentive and balanced (where there is no dominant haemodynamic disorder), thanks to which it may facilitate the selection of drugs. Using tailored pharmacotherapy may result in lower doses used, and thus increased compliance caused by fewer side-effects may result in better HT control.

The usefulness of ICG as a method for the development of targeted treatment of hypertension has been demonstrated in numerous studies. Xiajuan et al. used ICG to assess the relationship between systolic blood pressure and the haemodynamic parameters in apopulation in Shanghai [22]. Hypertensive patients in the study had a higher systemic vascular resistance index, which is confirmed by the results of the current study. However, data from hypertensive patients analyzed by Xiajuan et al. had significantly lower values of cardiac index $\left(2.6 \pm 1.0 \mathrm{~L} / \mathrm{min} / \mathrm{m}^{2}\right)$ compared to normotensive patients $\left(2.8 \pm 0.8 \mathrm{~L} / \mathrm{min} / \mathrm{m}^{2}\right)$. In the current study, patients in the pcHT group had a higher cardiac index, compared to those in the wcHT group $\left(3.2 \pm 0.63\right.$ vs $\left.3.0 \pm 0.6 \mathrm{~L} / \mathrm{min} / \mathrm{m}^{2}\right)$. One important reason for this difference may be that Xiujuan et al. analyzed patients with and without hypertension, while the current study focused on patients with well controlled and poorly controlled hypertension.

In a study conducted by Abdelhammed et al, 136 patients with hypertension were observed in which it is interesting to note that there were also noticed higher values of $\mathrm{CI}$ in the well-controlled HT group (RR120-140/80-90mmHg), compared to not controlled HT group, and ranged from $2.39 \pm 0.69 \mathrm{~L} / \mathrm{min} / \mathrm{m}^{2}(\mathrm{RR}<120 / 80 \mathrm{mmHg})-2.70 \pm 0.7 \mathrm{~L} / \mathrm{min} / \mathrm{m}^{2}$ (RR 120-140/80-90mmHg). In the current study, CI values were higher compared to Abdelhammed (mean 3.09 \pm 0.64 vs $2.56 \pm 0.61 \mathrm{~L} / \mathrm{min} / \mathrm{m}^{2}$ ). TFC also differed in the current study, and was higher than in Abdelhammed study [23].

In a study by Aoka et al, the patients were allocated to either a high resistance group (67\%), high output group (16\%) or a balanced group (17\%), based on their haemodynamic profiles. In the current study, patients with pcHT were stratified into these groups, as well as with rates of $42.1 \%$, $6,3 \%$, and $51.6 \%$, respectively (Tab. 3 ). In this case, the lower rates of high output may be explained by the average duration of HT, which was 10 years, and $51.6 \%$ of the pcHT population had already had beta-blocker treatment introduced (Tab. 4.).
The effectiveness of ICG in the development of targeted hypertension treatment has been proven to be superior when compared to standard treatment guidelines in two studies performed by Krzesiński et al. In one study, increased vascular resistance seemed to be the dominant mechanism of hypertension $[20,24]$. Smith et al. evaluated 164 patients with essential hypertension and obtained better office BP control in their ICG-guided group [25]. In another prospective, randomized and controlled trial, Taler et al. used ICG-based therapy in 104 resistant hypertensives and also achieved a higher frequency of goal office BP in ICG-guided group [18]. Fadl Elmula et al., in a small sample of patients with resistant $\mathrm{HA}$, reported a better BP lowering effect of pharmacotherapy adjusted to the individual haemodynamic profile [26].

In the current study, over $50 \%$ of patients with chronic hypertension had poorly controlled blood pressure and did not reach their therapeutic goal. There was a significant difference in haemodynamic profiles between the patients with well controlled and poorly controlled hypertension. This suggests that the pharmacologic therapies were not tailored to the pathology in each patients' haemodynamic profile. CCB were used more often in the wcHT compared to $\mathrm{pcHT}$ group (48.9\% vs $31.6 \%$; $\mathrm{p}=0.015)$ (Tab. 4.) Among the wcHT patients, high SVRI was less frequently observed (31.9\% vs $41.1 \%$; $\mathrm{p}<0.01$ ((Tab. 2.). This difference supports the reliability of ICG: more CCB (vasodilators) - lower SVRI. Thus, the study has presented information on the usefulness and accuracy of impedance cardiography in a primary care setting.

\section{Strengths and limitations}

The major strength of the study is that it was conducted on a population of patients treated in an outpatient setting and therefore reflects the haemodynamic state of the cardiovascular system of an average patient managed in the office of a family doctor. In addition to the haemodynamic profile, the drugs used by the patients and the effectiveness of their therapy were determined, and thus demonstrating the possibility of targeted hypertension treatment.

The limitations include the relatively small number of patients participating in the study and the fact that the studied population had various comorbidities (diabetes, coronary artery disease) in addition to hypertension. Also, the test was conducted with the patients in sitting position, which differed from the methodology of oither rearchers. Analysis of a visit-to-visit trend would have been useful, but there was only one ICG test of a single patient performed. Lastly, the patients came from only a single outpatient clinic; therefpre, the pharmacotherapy used may differ from that in other clinics.

\section{CONCLUSIONS}

Half of the examined patients did not achieve the therapeutic goals for hypertension treatment. Differences in haemodynamic state of well controlled and poorly controlled hypertension groups suggests the usefulness of impedance cardiography-targeted hypertension treatment.

\section{Acknowledgments}

This study was supported by funds from the Polish National Centre (Decision No. DEC-2012/07/B/NZ5/00017 and ST- 
72), which had no role in the study design, data collection and analysis, decision to publish, or preparation of the manuscript.

\section{REFERENCES}

1. Mills KT, Stefanescu A, He J. The global epidemiology of hypertension. Nat Rev Nephrol. 2020; 16(4): 223-237. doi: 10.1038/s41581-019-0244-2

2. Trzeciak BG, Siebert J, Gutknecht P, Molisz A, Filipiak KJ, WozakowskaKapŁon B. Cardiovascular risk factors determined via the internet in 2 periods of time: 2004-2009 and 2010-2015 in Poland. Int J Occup Med Environ Health. 2017; 30(3). doi: 10.13075/ijomeh.1896.00835

3. Trzeciak B, Gutknecht P, Molisz A, Siebert J. Fatal cardiovascular risk in Poland as determined via internet. Ann Agric Environ Med. 2017; 24(2). doi:10.5604/12321966.1235161

4. Cherry DK, Woodwell DA. National Ambulatory Medical Care Survey: 2000 summary. Adv Data. 2002; (328): 1-32. Accessed January 16, 2017 http://www.ncbi.nlm.nih.gov/pubmed/12661586

5. Niklas A, Flotyńska A, Puch-Walczak A, et al. Prevalence, awareness, treatment and control of hypertension in the adult Polish population - Multi-center National Population Health Examination Surveys WOBASZ studies. Arch Med Sci. Published online 2018. doi: 10.5114/ aoms.2017.72423

6. Using the Internet to Determine Fatal Cardiovascular Risk in the Polish Population. Forum Med Rodz. 2011; 5(3): 187-200. Accessed June 3, 2015. http://czasopisma.viamedica.pl/fmr/article/view/17982

7. Williams B, Mancia G, Spiering W, et al. 2018 ESC/ESH Guidelines for the management of arterial hypertension. Eur Heart J. 2018; 39(33): 3021-3104. doi:10.1093/eurheartj/ehy339

8. Hiremath S, Sapir-Pichhadze R, Nakhla M, et al. Hypertension Canada's 2020 Evidence Review and Guidelines for the Management of Resistant Hypertension. Can J Cardiol. 2020; 36(5): 625-634. doi: 10.1016/j. cjca.2020.02.083

9. Li R, Liang N, Bu F, Hesketh T. The effectiveness of self-management of hypertension in adults using mobile health: Systematic review and meta-analysis. JMIR mHealth uHealth. 2020; 8(3). doi: 10.2196/17776

10. Treciokiene I, Postma M, Nguyen T, et al. Healthcare professional-led interventions on lifestyle modifications for hypertensive patients - a systematic review and meta-analysis. BMC Fam Pract. 2021; 22(1): 63. doi: $10.1186 / \mathrm{s} 12875-021-01421-z$

11. Prosser HCG, Azzam O, Schlaich MP. Resistant Hypertension: Which Agent? Heart Lung Circ. 2018; 27(8): 911-916. doi: 10.1016/j. hlc.2018.02.013

12. Aoka Y, Hagiwara N, Kasanuki H. Heterogeneity of Hemodynamic Parameters in Untreated Primary Hypertension, and Individualization of Antihypertensive Therapy Based on Noninvasive Hemodynamic Measurements. Clin Exp Hypertens. 2013; 35(1): 61-66. doi: $10.3109 / 10641963.2012 .690469$
13. Khraim F, Pike R. Impedance Cardiography-Guided Treatment of Hypertension: A Review of the Literature. Can J Cardiovasc Nurs. Published online 2014.

14. Flack JM, Adekola B. Blood pressure and the new ACC/AHA hypertension guidelines. Trends Cardiovasc Med. 2020; 30(3): 160-164. doi: 10.1016/j.tcm.2019.05.003

15. Medina-Lezama J, Narvaez-Guerra O, Herrera-Enriquez K, et al. Hemodynamic patterns identified by impedance cardiography predict mortality in the general population: The PREVENCION study. J Am Heart Assoc. 2018; 7(18). doi: 10.1161/JAHA.118.009259

16. Rada MA, Cuffaro PE, Galarza CR, et al. Predictive value of non-invasive hemodynamic measurement by means of impedance cardiography in hypertensive subjects older than 50 years of age. Clin Exp Hypertens. 2014; 36(5): 280-284. doi: 10.3109/10641963.2013.810232

17. Dupuis M, Noel-Savina E, Prevot G, et al. Determination of Cardiac Output in Pulmonary Hypertension Using Impedance Cardiography. Respiration. Published online 2018. doi: 10.1159/000486423

18. Taler SJ, Textor SC, Augustine JE. Resistant hypertension: comparing hemodynamic management to specialist care. Hypertens (Dallas, Tex 1979). 2002; 39(5): 982-988. Accessed February 4, 2017. http://www. ncbi.nlm.nih.gov/pubmed/12019280

19. Siebert J, Gutknecht P, Molisz A, Trzeciak B, Nyka W. Hemodynamic findings in patients with brain stroke. Arch Med Sci. 2012; 8(2). doi: 10.5114/aoms.2012.28567

20. Krzesiński P, Gielerak G, Kowal J, Piotrowicz K. Usefulness of impedance cardiography in optimisation of antihypertensive treatment in patients with metabolic syndrome: A randomised prospective clinical trial. Kardiol Pol. 2012; 70(6): 599-607

21. Niklas A, Marcinkowska J, Kozela M, et al. Blood pressure and cholesterol control in patients with hypertension and hypercholesterolemia: The results from the Polish multicenter national health survey WOBASZ II. Polish Arch Intern Med. Published online 2019. doi: 10.20452/ pamw.15013

22. Xiajuan Z, Ding D, Yanyan H, Zhen H. Impedance cardiographic hemodynamic variables and hypertension in elderly Han residents. Ups J Med Sci. 2013; 118(2): 80-86. doi: 10.3109/03009734.2012.756959

23. Abdelhammed AI, Smith RD, Levy P, Smits GJ, Ferrario CM. Noninvasive hemodynamic profiles in hypertensive subjects. Am J Hypertens. 2005; 18(2 SUPPL.): 51S-59S. doi: 10.1016/j.amjhyper.2004.11.043

24. Krzesiński P, Gielerak G, Stańczyk A, et al. The effect of hemodynamically-guided hypotensive therapy in one-year observation: Randomized, prospective and controlled trial (FINEPATH study). Cardiol J. 2016; 23(2): 132-140. doi: 10.5603/CJ.a2016.0009

25. Smith RD, Levy P, Ferrario CM. Value of Noninvasive Hemodynamics to Achieve Blood Pressure Control in Hypertensive Subjects. Hypertension. 2006; 47(4).

26. Fadl Elmula FEM, Hoffmann P, Larstorp AC, et al. Adjusted drug treatment is superior to renal sympathetic denervation in patients with true treatment-resistant hypertension. Hypertension. 2014; 63(5): 991-999. doi: 10.1161/HYPERTENSIONAHA.114.03246 